\title{
Cape Town's Stormwater Ponds: investigating the amenity that they provide
}

\author{
Alastair Robert Rohrer ${ }^{1}$ and Neil Philip Armitage ${ }^{2}$ \\ rhrala001@myuct.ac.za ${ }^{1}$ \\ neil.armitage@uct.ac.za ${ }^{2}$ ORCID: orcid.org/0000-0003-3704-3648
}

\author{
Supervisor: Neil Philip Armitage \\ Department: Civil Engineering
}

\begin{abstract}
Stormwater ponds are frequently used in urban drainage systems to attenuate flood peaks. However, they additionally have the potential to provide amenities for surrounding communities in lines with current Sustainable Drainage System (SuDS) practice. Currently, the City of Cape Town is unaware if, or to what extent, amenity is being provided by their stormwater ponds. Thus, in order to enable insight to this problem, 77 of the 737 located stormwater ponds within Cape Town were individually investigated, i.e. an approximately $10 \%$ sample. The ponds included in this $10 \%$ sample were chosen based on a variety of characteristics aimed to create a fair reflection of all ponds in Cape Town. Approximately $51 \%$ of the investigated ponds were found to have incorporated desirable facilities in addition to their flood control abilities. Unfortunately, litter was found to plague many stormwater ponds, often severely in the less affluent areas of the City. Consequently, this contributed to $51 \%$ of the investigated ponds having a low aesthetic value. Thus, many of the ponds in Cape Town do currently provide some amenity yet it could be significantly improved by implementing more innovative SuDS design strategies.
\end{abstract}

Keywords: Stormwater ponds; Sustainable drainage systems (SuDS), Amenity 


\section{Introduction}

Stormwater ponds are a component of urban drainage systems that may be utilised for a number of different purposes other than the management of flood peaks for which they were originally conceived (Hancock et al., 2010). In addition to their flood management abilities, stormwater ponds can be effective water treatment devices that can improve the poor water quality associated with urban runoff. They may also provide diverse plant and wildlife ecosystems than can preserve natural biodiversity. Finally, they may provide various amenity benefits for the surrounding communities (Bayley et al., 2015). Each of these characteristics is individually more pronounced in the three main different types of stormwater ponds. The three different types of stormwater ponds are detention ponds, which are typically dry except for during and after storm events in which they detain water for short durations; retention ponds, which hold a permanent pool of water whilst attenuating floods; and constructed wetlands, which consist of largely vegetated areas with shallow pools of water.

In order to reduce the risk of flooding, the City of Cape Town has overseen the construction of some 800 stormwater ponds over the past few decades. Unfortunately, for various reasons, the City does not possess adequate as-built data on the geographical location and characteristics of each pond. This creates difficulty in assessing what services are being provided by Cape Town's ponds as a whole, particularly as to whether they are providing any amenity. Amenity is defined as a feature or facility that improves the comfort, convenience or the attractiveness of an area (Handy, 2002). This study aimed to investigate the City of Cape Town's stormwater ponds, inter alia, to deliver insight into what amenities they were providing. The main limitations imposed on the study were due to time and personal safety. Therefore, only a representative sample of the City's ponds could be investigated. Each investigated pond was only inspected once and only for a short duration. Further, personal safety measures meant ponds located in areas notorious for criminal activities were not investigated. The amenity was evaluated solely on a visual basis and by an engineer (a non-specialist in anthropological studies) alone. Determining if or to what extent amenity is currently provided in the City of Cape Town's stormwater ponds could enable insight into how amenity could be introduced or improved in Cape Town's stormwater pond system. 


\section{Methodology}

\subsection{Location and Classification of ponds}

Due to the inadequate City of Cape Town records of the approximately 800stormwater ponds - particularly when it came to amenity provided by each, it was first necessary that each stormwater pond be located and described.

The City of Cape Town's Metropolitan area covers a total of 245,500 hectares $\left(2455 \mathrm{~km}^{2}\right)$ (Ewart-Smith et al., 2008). To complete the study in an efficient manner, Geographical Information Systems (GIS) data was used to map and locate each individual pond within the City of Cape Town. Two different GIS data sets along with a set of paper print maps were used in order to locate and classify Cape Town's stormwater ponds. The first data set of GIS data that was retrieved from the Engineering and Built Environment (EBE) library in Centlivres Building at the University of Cape Town. This data set was compiled by the City of Cape Town in 2008 (Ewart-Smith et al., 2008). It documents all waterbodies within the Cape Town Metro Municipality area. The second GIS data set and the paper print maps were obtained from employees of the City of Cape Town's Stormwater and Sustainability Division. This GIS data set located the stormwater ponds in Cape Town present in 2005 and paper print maps displayed the position of stormwater ponds within each of the eight municipal districts within Cape Town. The paper print maps displayed the position of existing stormwater ponds in 2008 with changes after 2008 until 2012 being manually drawn onto the maps by hand (Austin, Personal Communication 2014, October 1). Unfortunately, none of the data that was retrieved provided a classification for the type of stormwater pond and some of data was out-dated.

A new, more complete, digital GIS data set that recorded the location and classification of all stormwater ponds within the City of Cape Town was constructed by synthesising the available data. Through this synthesis, inaccuracies in the data sets could be determined through comparison. The process was performed using the programs ArcMap 10.2 and Google Earth. By overlaying a basemap (an orthorectified image that displays satellite imagery) of $5 \mathrm{~m}$ resolution into ArcMap 10.2, it was possible to visually inspect each pond within the newly created GIS data and to classify them according to various criteria which will shortly be described. In some instances, Google Earth Street View was used in order to classify the pond 
when using the basemap proved difficult. This entire process enabled the identification and classification of 737 of Cape Town's stormwater ponds. The location and classification of each pond, along with its area, suburb, nearest road, erf-number, co-ordinates, and original identification number, were recorded in a stormwater pond register that was specially compiled for the study.

\subsection{Pond Investigations}

In order to gain perspective on what amenity is present in the City of Cape Town's stormwater ponds selected ponds were individually inspected. The ponds were chosen so that, as far as was reasonably possible, they represented all of the stormwater ponds within the City of Cape Town. The sample was chosen according to the following criteria:

i) Each of the three different types of stormwater ponds were well represented,

ii) Stormwater ponds of different sizes,

iii) The affluence of area in which the stormwater pond was situated which was determined using Romanovsky \& Gie's (2006) study on level of living index per suburb for the City of Cape Town, and

iv) Each of Cape Town's the major catchments were represented.

Due to personal safety measures, areas with a known reputation for criminal activity were avoided. Unfortunately, many of Cape Town's ponds are found in areas deemed unsafe which eliminated a large number of ponds that could be investigated. Each day, a selection of ponds that were situated closely to one another (to reduce transport costs) was investigated. The investigations were conducted for six days, respecting imposed limitations and ensuring all of the specified criteria were accounted for. In all, seventy-seven, of the total 737 located, ponds were visited making a sample size of $10.44 \%$.

The assessments of amenity conducted during the pond investigations were based solely on visual observations due to time constraints and scope of the study. The basic data for each pond was recorded on a 'Pond Investigation Survey Sheet' that was composed before the investigations began. These survey sheets were used 
to record the size, type of stormwater pond, affluence of area and location of each pond that was investigated. Various elements of relevance to the provision of amenity, suggested by Moore \& Hunt (2012) were documented. The elements that were investigated were the following:

i) The aesthetic value of the pond based on the rating system described in Section 3.1,

ii) Evidence of maintenance such as cut grass, removal of litter or upkeep of signs or pathways,

iii) Potential for multiple purposes,

iv) Presence of litter, fencing, infiltration, squatting or significant drowning risk, and

v) Approximate distance from existing/new developments.

The survey sheet also recorded comments relevant to water quality and presence of biodiversity as both of these aspects can have a large impact on amenity (Lee \& Li, 2009; Moore \& Hunt, 2012).

\section{Results and Discussion}

\subsection{Aesthetic Value}

The level of amenity that an area provided is largely dependent on its aesthetic qualities (Handy, 2002). Stormwater ponds impose a visual impression on the community in which they are situated. Thus, by assessing the aesthetic value of a pond, it is possible to gain insight into the level of amenity that the pond provides. The aesthetic value of stormwater ponds within the City of Cape Town was classified according to the following description:

i) High - The pond is highly maintained and/or incorporates a diversity of plant life and foliage. The pond contributes highly to the aesthetic appeal of the area and creates an attractive feature. 
ii) Medium - The pond is maintained and neat looking. The pond fits well into the area and provides a slight enhancement to the aesthetic appeal of the area.

iii) Low - The pond is unkempt and provides no contribution to the aesthetic appeal of the area. Ponds are often suffering from overgrowth of vegetation, surface material erosion or marshy basin floors. Litter is often clearly visible.

iv) Very Low - The pond is unmaintained and degrades the aesthetic value of the area. The ponds are often huge litter traps and have become dumping areas.

The type of stormwater pond has a significant impact on the aesthetic value. It was revealed that $63 \%$ of the detention ponds that were investigated only offered an aesthetic value in the range: very low to low. In comparison, $73 \%$ of the retention ponds and $75 \%$ of wetlands that were investigated provided a medium to high aesthetic appeal. This result concurs with previous studies and is largely due to the aquatic appeal that both retention ponds and wetlands can provide (Lee \& Li, 2009). The wetlands and retention ponds that were investigated both often provided a diverse plant and wildlife ecosystems creating suitable habitats for many avifauna and waterfowl species as can be seen in Figure 1. Many of the detention ponds that were investigated however, had a low aesthetic appeal, as they had become litter traps or dumping grounds. Further, many of the basin floors of detention ponds were marshy due to groundwater infiltration. Many of the detention ponds floors had been badly worn leaving patchy grass areas. The study further revealed that the size of the

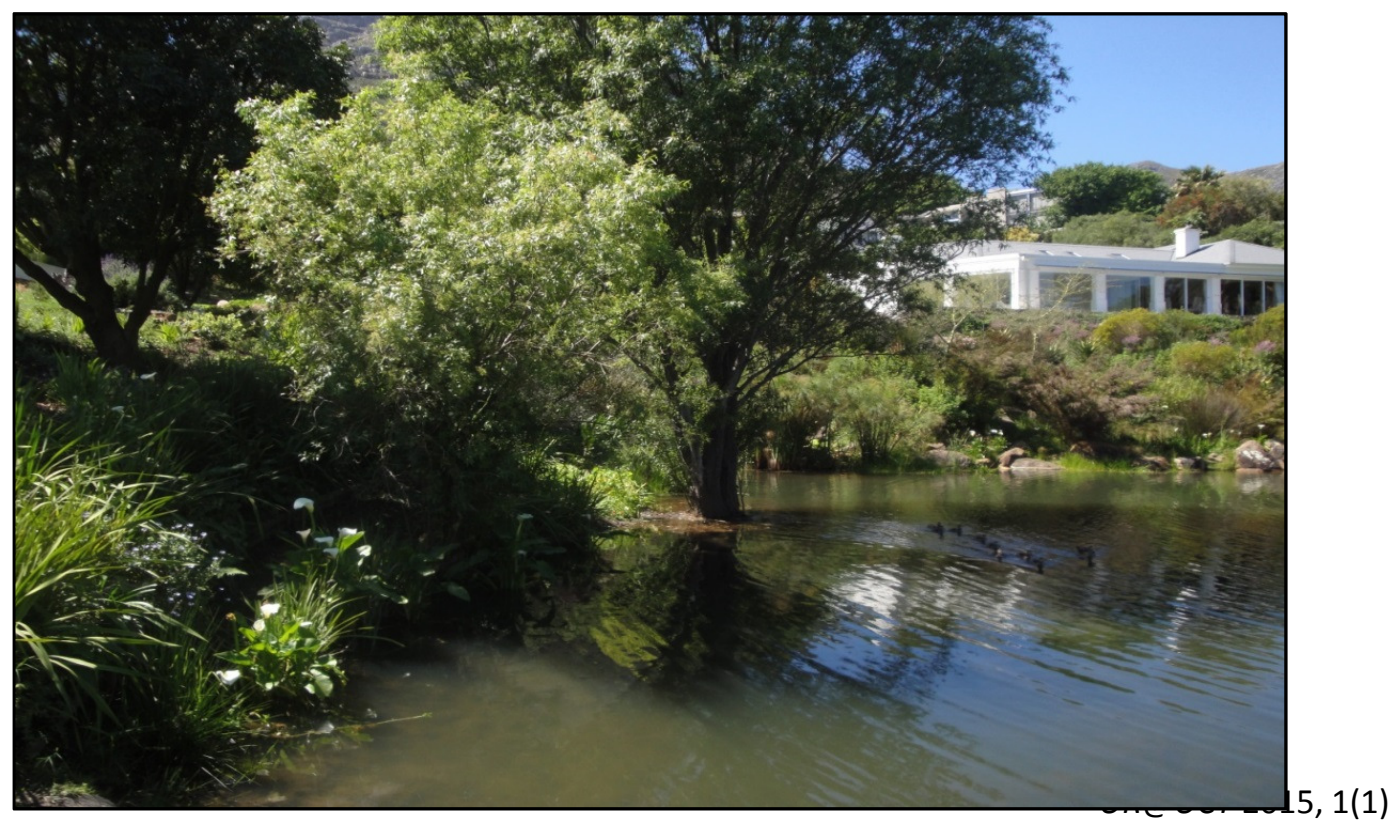

Figure 1: An example of a retention pond that provides diverse plant and wildlife ecosystems 
stormwater pond had minimal impact on the aesthetic value provided.

The affluence of the area in which a stormwater pond is situated was shown to have a highly significant impact on the aesthetic value of the pond. By analysing the correlation between the aesthetic value and affluence of the area, the study showed that there was a correlation between affluence and aesthetic value - as was expected. This result is showed in Table 1. The affluence of the area in which the pond was located was determined using the categorisation described in using Romanovsky \& Gie's (2006) study and determined by visual inspection made during the pond inspections. The levels of affluence are described by the following:

i) Very High - The area exclusively holds low-density, large-scale private formal housing. Houses have large gardens and numerous high-value household assets are conspicuous. Houses incorporate numerous security measures.

ii) High - The area exclusively holds low-density, private formal housing. Houses have large to medium sized gardens and household assets are evident.

iii) Medium - The area holds medium to low-density private formal housing. The area is well serviced and the needs of these areas relates to maintenance of existing services and public areas.

iv) Low - The area contains a mixture of high-density, private and government formal housing. The area shows depressed physical, economic and social environments. Nevertheless, households show evidence of receiving some form of household water reticulation and sanitation.

v) Very Low - The area predominantly holds high-density, informal housing. The area shows evidence of mass unemployment and social problems associated with poverty. Further, basic services are provided at a community level through communal standpipes and sanitation. Backyard shacks are evident in these areas (Romanovsky \& Gie, 2006) 
Table 1: Dispersion of the aesthetic value of investigated ponds per affluence area

\begin{tabular}{|l|l|l|l|l|l|}
\hline \multirow{2}{*}{ Affluence of area } & \multicolumn{5}{|c|}{ Aesthetic Value } \\
\cline { 2 - 6 } & \multirow{2}{*}{ High } & Medium & Low & $\begin{array}{l}\text { Very } \\
\text { Low }\end{array}$ & Total \\
\hline Very High & 7 & 1 & 0 & 1 & 9 \\
\hline High & 11 & 7 & 5 & 4 & 27 \\
\hline Medium & 1 & 1 & 4 & 4 & 10 \\
\hline Low & 1 & 6 & 6 & 6 & 19 \\
\hline Very Low & 0 & 0 & 2 & 5 & 7 \\
\hline Total & 20 & 15 & 17 & 20 & 72 \\
\hline
\end{tabular}

* Five of the investigated ponds were under construction and so did not contribute to the study

The poor aesthetic ratings attributed to lower affluent areas shown in Table 1 were often a consequence of the large amounts of litter that is often present in these areas. This problem was often exacerbated by illegal dumping - which also negatively affects aesthetic value. Ponds in lower affluent areas also often lacked evidence of significant fauna and flora. Further, the majority of the ponds located within lower affluent areas were detention ponds, which as mentioned previously, tended to a have much lower aesthetic appeal in comparison to retention ponds or wetlands.

\subsection{Multiple Uses for Stormwater Ponds}

The large land requirements that stormwater ponds often demand can be exploited to serve multiple uses such as creating desirable facilities for the surrounding community in addition to their role of attenuating stormwater runoff. Many of the ponds that were investigated throughout the City of Cape Town incorporated dual use. The most notable uses found in the investigated ponds were the following:

i) Educational signage, 
ii) Play parks,

iii) Public open space,

iv) Relaxation areas,

v) Sports fields,

vi) Walking trails, and

vii) Other

In this study, a relaxation area was differentiated to public open space based on the restriction of access. Relaxation areas were defined to occur only in private or gated developments whereas public open spaces are freely accessible to all members of the public and are maintained by the City of Cape Town. The category defined as 'other' typically included aspects such as flower gardens. The type of dual use incorporated varied based on the affluence of the area. Table 2 provides a breakdown of the number of ponds that incorporate multi-functionality linked to the affluence of the surrounding area.

Table 2: Detail of dispersion of multiple use ponds per affluence area

\begin{tabular}{|c|c|c|c|c|c|c|}
\hline \multirow{2}{*}{$\begin{array}{c}\text { Multiple } \\
\text { Functionality }\end{array}$} & \multicolumn{6}{|c|}{ Affluence of Area } \\
\hline & $\begin{array}{l}\text { Very } \\
\text { h }\end{array}$ & High & Mediu & Low & $\begin{array}{l}\text { Very } \\
\text { Low }\end{array}$ & Total \\
\hline $\begin{array}{l}\text { Educational } \\
\text { infrastructure }\end{array}$ & 0 & 3 & 0 & 1 & 0 & 4 \\
\hline Play Park & 0 & 1 & 2 & 1 & 0 & 4 \\
\hline Public Open Space & 3 & 3 & 0 & 1 & 0 & 7 \\
\hline Relaxation Area & 1 & 5 & 0 & 0 & 0 & 6 \\
\hline Sports field & 0 & 0 & 1 & 4 & 1 & 6 \\
\hline Walking Trail & 3 & 2 & 3 & 0 & 0 & 8 \\
\hline Other & 0 & 1 & 0 & 0 & 1 & 2 \\
\hline $\begin{array}{l}\text { Total of Multiple } \\
\text { Use Ponds }\end{array}$ & 7 (78\%) & $\begin{array}{l}15 \\
\%)\end{array}$ & \begin{tabular}{|c|}
6 \\
$\%)$
\end{tabular} & $7(39 \%)$ & $2(38 \%)$ & $\begin{array}{c}37 \\
\%)\end{array}$ \\
\hline No Multiple uses & $2(22 \%)$ & 12 & 4 & 12 & $5(62 \%)$ & 35 \\
\hline
\end{tabular}




\begin{tabular}{|l|l|l|l|l|l|l|}
\hline & & $\%)$ & $\%)$ & $\%)$ & & $\%)$ \\
\hline Total Ponds & $\mathbf{9}$ & $\mathbf{2 7}$ & $\mathbf{1 0}$ & $\mathbf{1 8}$ & $\mathbf{8}$ & $\mathbf{7 2}$ \\
\hline
\end{tabular}

* Five of the investigated ponds were under construction and so did not contribute to the study

Table 2 indicates that areas of very high affluence contain the highest proportion of multi-functional ponds. In very high affluent areas, multi-functional ponds were frequently incorporated as walking trails, such as the Constantia Greenbelt, or they were relaxation areas or public open spaces that took advantage of a naturally attractive setting. These ponds were often located in open spaces that were well-maintained and allowed recreational activities to occur. High affluent areas had the most diverse multi-functional ponds. Many of the ponds had educational infrastructure that taught the public about the history and/or biodiversity of the area in which the pond was located. An example of this infrastructure can be seen in Figure 2. These ponds with educational infrastructure were often located within nature reserves or public parks that were highly maintained. Only $56 \%$ of the ponds located in areas of a high affluence level served some form of dual use. This percentage was surprisingly low when there is such a high demand for space in these areas. 


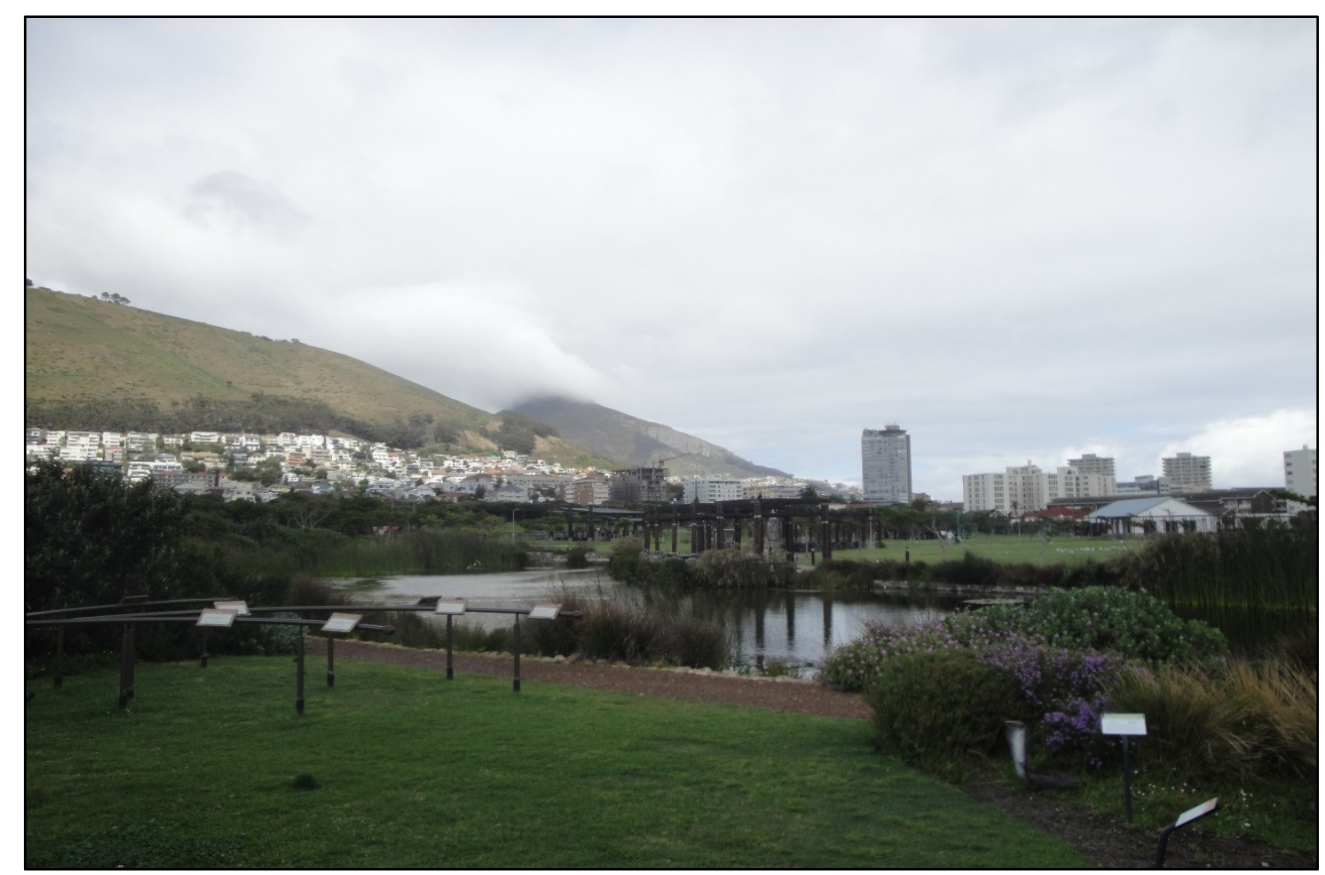

Figure 2: A retention pond that provides an educational multifunctionality

As the level of affluence decreased, it became evident that ponds being used as public open spaces or walking trails also declined. This result was expected, as these areas can often be associated with high crime rates due to the reduction in the line of sight. The majority of multi-functional ponds in the low affluent areas were sports fields. Multiple purpose ponds serving as sports fields are common and it is an effective way to make use of the space in an efficient manner. Unfortunately, as many of ponds are grass lined, using them as a sports field can cause erosion of the grass and the eventual degradation of the pond as seen in Figure 3. Table 2 also indicates that as the affluence of the area decreases the percentage of ponds having multiple uses also decreases. $78 \%$ of ponds located in areas of a very high affluence area had multi-functionality whereas only $38 \%$ of ponds located in areas of a very low affluence had multi-functionality. Only $51 \%$ of the total ponds investigated qualified as multi-use stormwater ponds. This percentage of ponds was low considering the large array of potential uses stormwater ponds can have as well as the significant value a multi-use pond can add to the area. 


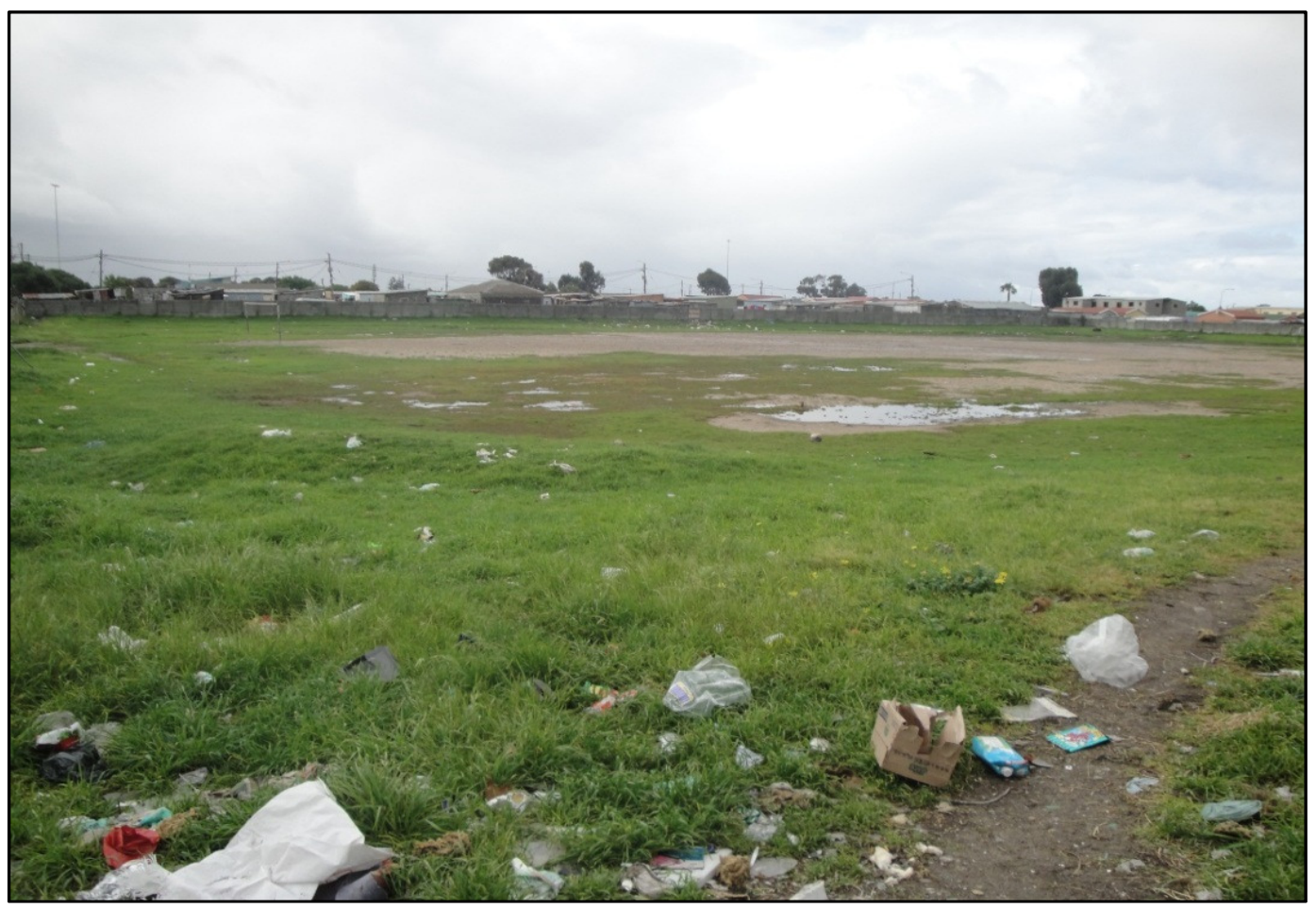

Figure 3: A detention pond in a low affluent area in which dual use has led to the erosion surface material

The different types of stormwater were found to incorporate a mixture of different uses within ponds to provide multi-functionality. Table 3 indicates the dispersion of multi-functional purpose ponds amongst different types of stormwater ponds. Both retention ponds and constructed wetlands have been largely exploited their potential for multi-functionality throughout the City of Cape Town through the creation of points of attraction such as: educational infrastructure, walking trails, public open spaces or relaxation areas. Over $70 \%$ retention ponds and constructed wetlands (combined) incorporated multi-functionality. This is easily explained as retention ponds and wetlands create a natural water attraction if they are well maintained. Therefore, it is often easier simpler to create multi-functional public spaces around these types of ponds.

Table 3: Dispersion of multiple purpose stormwater ponds per type of stormwater pond

\begin{tabular}{|l|l|}
\hline Multiple Functionality & Stormwater Pond Type \\
\hline
\end{tabular}




\begin{tabular}{|c|c|c|c|c|}
\hline & Detention & Retention & Wetland & Total \\
\hline $\begin{array}{l}\text { Educational } \\
\text { infrastructure }\end{array}$ & 0 & 1 & 3 & 4 \\
\hline Play Park & 4 & 0 & 0 & 4 \\
\hline Walking Trail & 3 & 2 & 3 & 8 \\
\hline Public Open Space & 3 & 4 & 0 & 7 \\
\hline Relaxation Area & 3 & 3 & 0 & 6 \\
\hline Sports field & 6 & 0 & 0 & 6 \\
\hline Other & 1 & 1 & 0 & 2 \\
\hline $\begin{array}{l}\text { Total of Multiple } \\
\text { Use ponds }\end{array}$ & $20(41 \%)$ & $11(73 \%)$ & $6(75 \%)$ & $\begin{array}{l}37 \\
(51 \%)\end{array}$ \\
\hline No Multiple uses & $29(59 \%)$ & $4(27 \%)$ & $2(25 \%)$ & $\begin{array}{l}35 \\
(49 \%)\end{array}$ \\
\hline Total Ponds & 49 & 15 & 8 & 72 \\
\hline
\end{tabular}

* Five of the investigated ponds were under construction and so did not contribute to the study

The multi-functional use of detention ponds is often more difficult to exploit. Detention ponds are not naturally points of attraction in urban areas and so achieving dual use can become challenging and calls for innovative engineering. Further, the inclusion of amenities can restrict their flood control abilities (Bayley et al., 2015). $41 \%$ of the detention ponds that were investigated showed evidence of multifunctional use. Detention ponds functioning as sports fields and play parks were the most common form of multi-functionality found in the inspected detention ponds. A number of the detention ponds that were investigated were used as public open spaces or were included in walking trails. However, the nature of this type of multifunctionality is largely dependent on the natural environment and level of maintenance that the area receives. The three detention ponds that were investigated on a walking trail were located in an area of a very high affluence level where crime rates were low, the natural environment had broad biodiversity and the area was well maintained by local residents. Detention ponds of this nature are often not possible in areas of a low affluence as the areas easily become crime-ridden and can become natural dumping areas for residents. 


\subsection{General Negative Amenity Contributions}

During the pond investigations, the survey recorded certain negative attributes. Those that were documented are listed on the horizontal axis of Figure 4. In the instances where infiltration had caused visible marshy areas on the basin of the pond, it was considered a negative attribute (Figure 5). Fencing of the pond was also considered a negative amenity, as it potentially restricted access. The negative amenity 'litter trap' was defined as a pond would naturally accumulate litter, which was from the accumulation of litter in the outlet of the pond. However, 'litter present' was simply defined by obvious litter visible around the area of the pond.

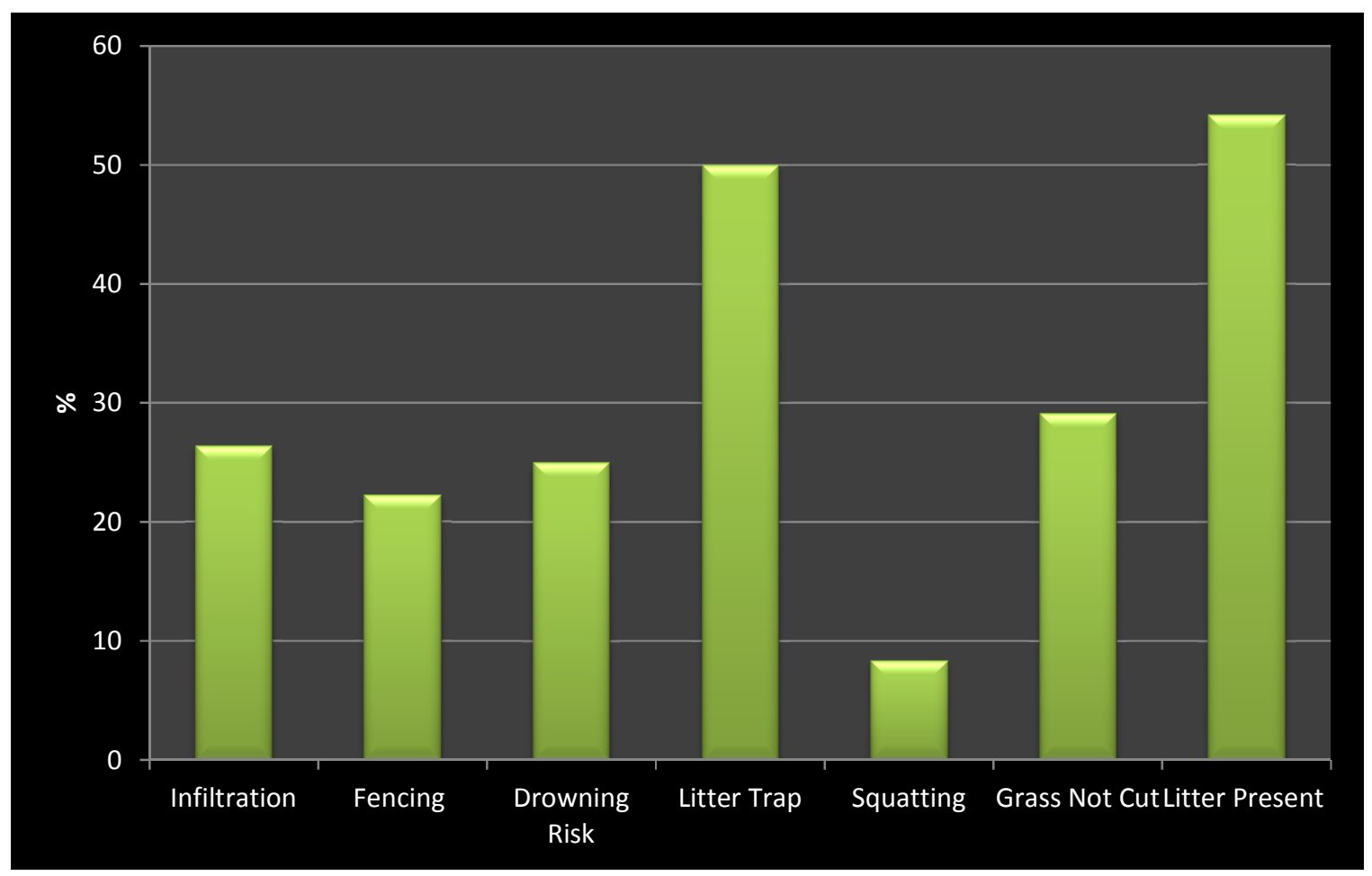

Figure 4: Percentages of negative amenity contributions that were present in investigated ponds

The general percentage of negative amenities attributed to the investigated ponds was low. Certain retention ponds posed drowning risks however, this is a typical disadvantage associated with retention ponds. On visual inspection, only $8 \%$ of the ponds showed evidence of squatting. However, it was revealed during discussions with City of Cape Town officials that squatting in stormwater ponds is a 
persistent problem that the City of Cape Town faces on a continual basis. This problem is monitored by the Anti-Land Invasion Unit (ALIU) but unfortunately, persistent reinvasion of evacuated land often occurs (Persent, Personal Communication 2014, October 1). It was clear that most ponds did receive some

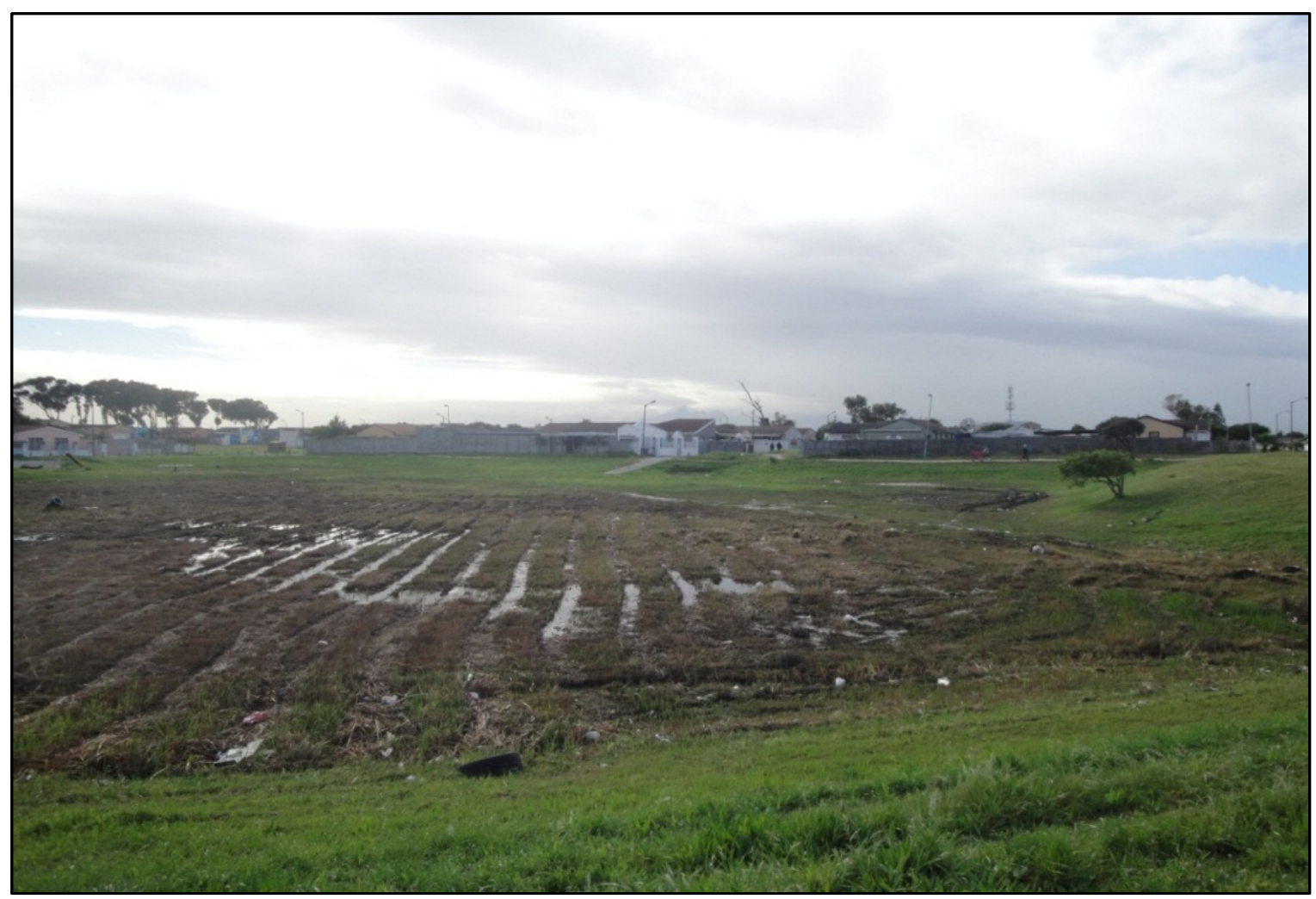

Figure 5: Degradation of amenity due to infiltration

form of maintenance, as it was apparent that only $29 \%$ of the ponds had not had their grass cut.

The most notable negative attribute associated to the investigated ponds was 'litter present'. $53 \%$ of the total ponds that were investigated had clearly visible litter. Further, $50 \%$ of the total investigated ponds were 'litter traps' and visible litter ponds' outlet. Upon interviews with local residents during pond investigations and with subsequent interviews with City of Cape Town officials, litter was the most often reported problem with the City's stormwater ponds. The abundance of litter within the ponds originates from on-site dumping and littering as well as litter entering the stormwater network and then being deposited into the pond. The litter has severe negative impacts on the ponds, reducing the ponds' storage capacity by blocking 
outlets as well hugely reducing its aesthetic appeal. An example of this can be seen in Figure 6.

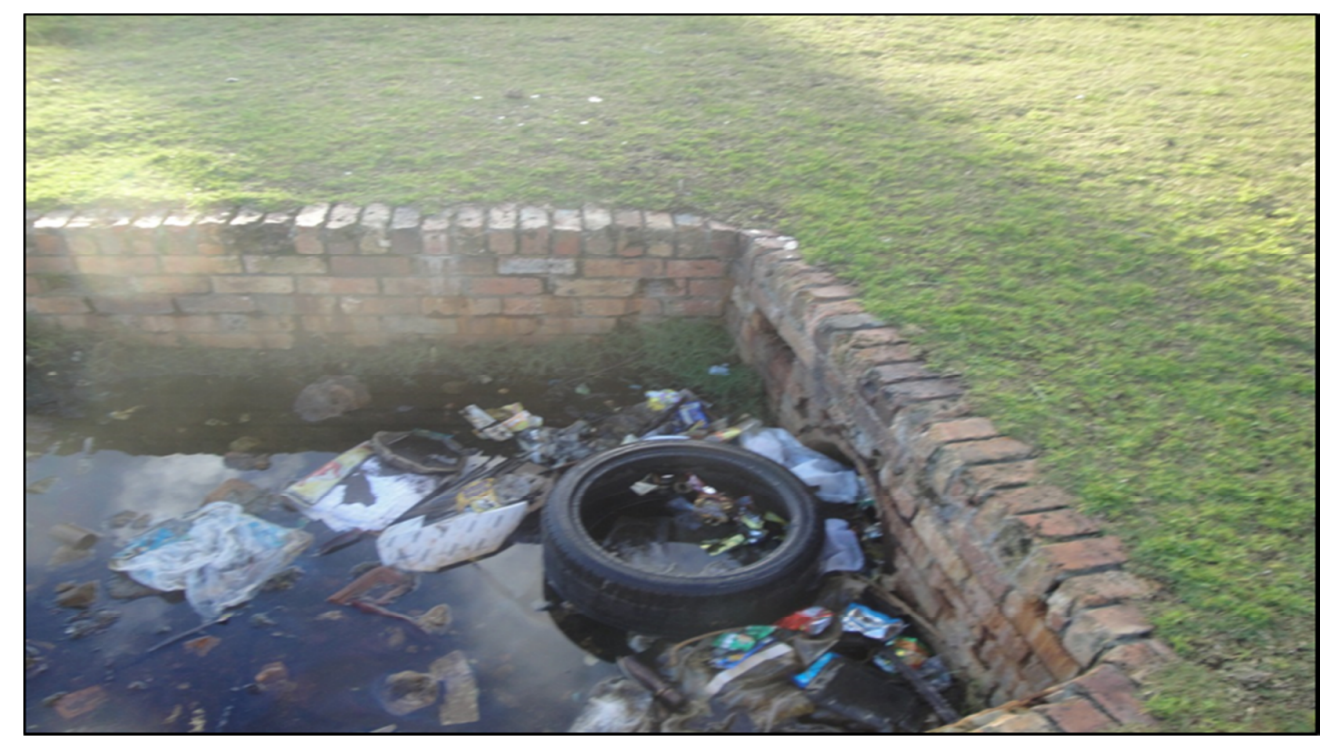

Figure 6: A stormwater pond classified as 'litter trap' due to litter accumulating in the outlet

In further analysis of the investigated ponds, it was evident that the percentage of ponds in which litter is present increases with decreasing affluence (Figure 7). A possible reason for this result could be due to the number of backyard shacks or informal dwellings in less affluent areas. Catering for refuse collection for these types of dwellings is a huge challenge (City of Cape Town, 2014). From Figure 4 and 7, it is

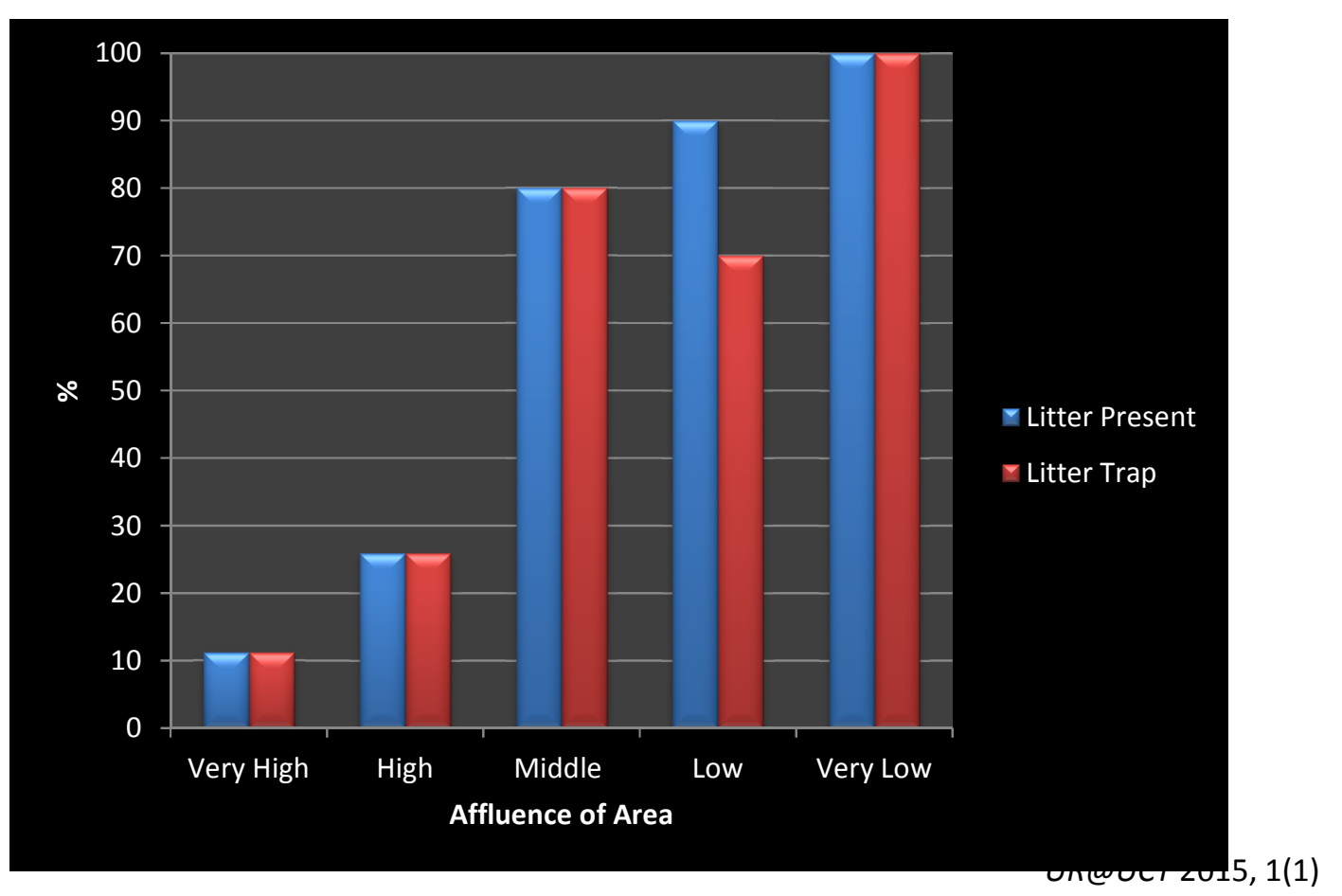

Figure 7: Percentage of pond per affluence area in which litter is present or is associated as a litter trap 
clear that litter is a large problem associated with Cape Town's stormwater ponds.

In a meeting conducted with a City of Cape Town official, it was clear that the City was well aware of the litter problem that plagues many of the stormwater ponds. Hence, numerous clean-up programs have been implemented to try to overcome the litter problem. Each of Cape Town's municipal districts has their own maintenance teams working on cleaning the ponds on a weekly basis. Further, maintenance programs such as the Expanded Public Works Program (EPWP), creates jobs for unskilled labourers among the communities to clean and pick up litter among the ponds in their areas. There also exists the 'Winter Readiness Program' in which each district initiates cleaning and preparation of their ponds for the upcoming winter. The removal of foliage debris and sediment is incorporated in the maintenance programs. Education programs conducted by the EPWP have further tried to educate communities about litter however; these educational programs have only proven to be successful for very brief durations (Persent, Personal Communication 2014, October 1).

Although many maintenance programs have been implemented they are still failing to deal with the quantity of litter ending up in Cape Town's stormwater ponds. From the information gathered from discussions with City officials, the biggest obstacle that the City faces in overcoming these problems is the lack of staff and financial resources. A further complication to maintenance programs is that some cleaning or maintenance activities require Environmental Management Programs (EMP). These EMPs are to be included in site-specific maintenance plans for surface infrastructure (Austin, Personal Communication 2014, October 3). In an effort to reduce the amount of ponds the Stormwater and Sustainability Branch have to maintain, they try to create parks in ponds. Not only does this allow the pond to become multi-functional, it also means that Cape Town City Parks will be in control of the maintenance of that pond. Unfortunately, City Parks faces a similar problem of a lack of resources and so they are not often able or willing to take on the maintenance requirements of the ponds. Action has been taken to try and clean up Cape Town's ponds however, the litter problem is not a fault of the engineering of the pond but rather a social problem of the community in which the pond is located. 


\subsection{Distance of ponds to Nearest to Development}

The location of a stormwater pond can have a significant impact on the value of a development. Multi-functional ponds have been known provide a positive influence on property value whereas uni-use ponds can negatively affect a property's value if it is not maintained properly (Lee \& Li, 2009). Table 4 indicates the distance of stormwater ponds to their nearest development. 'Contained within development' referred to ponds that were located within a private development that had restricted access. The category 'Borders development properties' referred to ponds whose property boundary was located directly adjacent to other existing infrastructure. All other distances referred to the distance in meters that the pond was located to the nearest property. All of the distances were visually determined during the site inspections.

Table 4: Distance of ponds to nearest developments

\begin{tabular}{|l|l|l|l|}
\hline \multicolumn{1}{|c|}{$\begin{array}{c}\text { Distance to nearest } \\
\text { Development }\end{array}$} & $\begin{array}{c}\text { Multiple } \\
\text { purpose }\end{array}$ & $\begin{array}{c}\text { No Multiple } \\
\text { purpose }\end{array}$ & \multicolumn{1}{|c|}{ Total } \\
\hline $\begin{array}{l}\text { Contained within } \\
\text { development }\end{array}$ & $10(77 \%)$ & $3(23 \%)$ & 13 \\
\hline $\begin{array}{l}\text { Borders development } \\
\text { properties }\end{array}$ & $14(42 \%)$ & $19(58 \%)$ & 33 \\
\hline $\pm 50 \mathrm{~m}$ & $7(46 \%)$ & $8(54 \%)$ & 15 \\
\hline $\pm 100 \mathrm{~m}$ & $5(50 \%)$ & $5(50 \%)$ & 10 \\
\hline $\pm 500 \mathrm{~m}$ & $1(100 \%)$ & $0(0 \%)$ & 1 \\
\hline Total & 37 & 35 & 72 \\
\hline
\end{tabular}

* Five of the investigated ponds were under construction and so did not contribute to the study

Table 4 indicates that $77 \%$ of the ponds that were contained within a development incorporated dual use. This result was to be expected due to the policies that are in place that state private development must release their stormwater runoff equivalent to the pre-development conditions (City of Cape Town, 2013). Stormwater ponds within these developments are often used to treat the runoff whilst also being designed to encourage multi-functionality. 
The results displayed in Table 4 showed that $85 \%$ of the total investigated stormwater ponds were located within approximately fifty meters of some form of development. At greater distances from developments, the number of existing ponds diminishes. This result is to be expected, yet it emphasises the importance of stormwater ponds incorporating desirable facilities to enhance surrounding areas whilst continuing to attenuate runoff to protect developments from flooding.

\section{Conclusions}

Amenity refers to the quality or pleasantness of a place and how it affects the way that people experience it (Handy, 2002). Thus, incorporating amenity into the design of a stormwater pond can greatly improve the public perception of the pond. The aesthetic value of a pond plays a vital role on the amenity provided. This study revealed that over $50 \%$ of the investigated stormwater ponds within Cape Town are associated with a negative aesthetic value. It was further revealed that on average detention ponds, the most frequently occurring type of pond generally had a lower aesthetic value compared to retention ponds and wetlands. These low aesthetic values were often attributed to negative amenities, in particular the abundance of litter present in Cape Town's stormwater ponds. 54\% of the investigated ponds had litter present or had become a dumping ground of some sort. Litter not only affects the aesthetic appeal but also affects the water storage and water treatment performance of the pond. Litter is one of the largest problems that Cape Town's ponds face, particularly in the lower affluent areas.

Additionally, the City of Cape Town has yet to exploit the full potential for the incorporation for amenity within all of it stormwater ponds. Only $51 \%$ of the investigated ponds incorporated multi-functionality of which the majority of dual-use was found in retention ponds and wetlands. For these types of ponds, it is often easier to introduce multi-functionality such as public open space due to their natural scenic environment. On the other hand, the majority of detention ponds had not incorporated multi-functionality. The City of Cape Town could try to be more innovative and create some form of amenity to make better use within their uni-use detention ponds. Nonetheless, this study revealed that many of Cape Town's stormwater ponds are providing amenities to their surrounding communities. However, there is room for improvement. 


\section{References}

Bastien, N.R.P., Authur, S. \& McLoughlin, M.J., 2012. Valuing amenity: public perceptions of sustainable drainage systems ponds. Water and Environment Journal, (26), pp.19-29.

Bayley, S.E. et al., 2015. Replacing natural wetlands with stormwater management facilities: Biophysical and percieved social values. Water Research, 73, pp.17-28.

City of Cape Town, 2013. Minimum Standards for Civil Engineering Services in Townships. Cape Town: City of Cape Town- Transport for Cape Town.

City of Cape Town, 2014. Incorporating Integrated Waste Management Plan. Sector Plan. Cape Town: The City of Cape Town Solid Waste Management.

Ewart-Smith, J. et al., 2008. Revised Wetland GIS Cover for the City of Cape Town. Cape Town: The Freshwater Consulting Group.

Hancock, G.S., Holley, J.W. \& Chambers, R.M., 2010. A Field-Based Evaluation of wet retention ponds: How Effective are Ponds at Water Quality Control? American Water Research Association, 46(10).

Handy, S., 2002. Amenity and Severance. In D. Hensher \& K. Button, eds. Handbook of Transport and the Environment. University of California at Davis: Oxford: Elsevier Science.

Lee, J.S. \& Li, M.-H., 2009. The impact of detention basin design on residential property value: Case studies using GIS in hedonic price modeling. Landscape and Urban Planning, 1(89), pp.7-16.

Moore, T.L.C. \& Hunt, L.H., 2012. Ecosystem service provision by stormwater pondsA means for evaluation? Water Research, 46, pp.6811-23.

Romanovsky, P. \& Gie, J., 2006. The spatial distribution of socio-economic status, service levels and levels of living in the City of Cape Town 2001- To highlight suburbs in need. Cape Town: Information \& Knowledge Management Department Strategic Information Branch The City of Cape Town.

Visage, J. \& Posel, D., 2013. A reconsiderarion of what and who is middle class in South Africa. Development Southern Africa, 30(2), pp.149-67. 
http://journals.uct.ac.za/index.php/UR

DOI 10.15641/ur-at-uct.v1i1.30

Winter, K., 2014. River Stretch Analysis. Survey. Cape Town: University of Cape Town. 